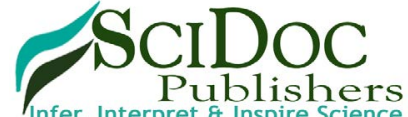

Publishers
International Journal of Dentistry and Oral Science (IJDOS)

ISSN: $2377-8075$

\title{
Evaluation of the Flexibility, Cyclic Fatigue, and Torsional Resistance of Rotary Endodontic Files Made of Different Nickel-Titanium Alloys
}

Research Article

Lopes $\mathrm{HP}^{1}$, Lopes WSP2 2 Vieira VTL ${ }^{3}$, Elias $\mathrm{CN}^{4}$, Cunha $\mathrm{RS}^{5 *}$

${ }^{1}$ Department of Endodontics, School of Dentistry, Estácio de Sá University, Rio de Janeiro, Brazil.

${ }^{2}$ Advanced Specialty Program, Brazilian Association of Dentistry, Juiz de Fora, Minas Gerais, Brazil.

${ }^{3}$ Department of Endodontics, Grande Rio University, Rio de Janeiro, Brazil.

${ }^{4}$ Department of Materials Science, Military Institute of Engineering, Rio de Janeiro, Brazil.

${ }^{5}$ Division of Endodontics, University of Manitoba, Manitoba, Canada.

\section{Abstract}

Aim: This study compared the mechanical properties of Profile Vortex, Profile Vortex Blue, and Race rotary files. Materials and Methods: The files were subjected to flexibility, rotating-bending (static and dynamic), and torsional resistance tests.

Results: Analysis of the data obtained was performed using ANOVA and Student-Newman-Keuls tests. Significant difference in flexibility was observed between Profile Vortex Blue and the two other files tested (Profile Vortex M Wire and Race) $(\mathrm{P}<0.05)$; however, Profile Vortex M Wire and Race did not significantly differ from each other $(\mathrm{P}>0.05)$. In the rotatingbending tests (static and dynamic), Profile Vortex Blue presented significantly greater resistance than Profile Vortex M Wire and Race $(\mathrm{P}<0.05)$. As for the torsional resistance test, Profile Vortex M Wire had significantly greater resistance (degrees and turns) than the other two instruments tested $(\mathrm{P}<0.05)$. No difference in torsional resistance was observed between Profile Vortex Blue and Race files $(\mathrm{P}>0.05)$. Statistical analysis revealed significant differences in maximum torque among the instruments tested, as follows (in decreasing order): Profile Vortex Blue $>$ Profile Vortex M Wire $>$ Race $(\mathrm{P}<0.05)$. Conclusion: Profile Vortex Blue files were more flexible, more resistant to rotating-bending fatigue, and to torsional failure when compared to Profile Vortex (made of M-Wire NiTi) and Race files (made of conventional NiTi).

\section{Introduction}

From a mechanical standpoint, the root canal anatomy has always been a challenge during cleaning and shaping [1,2]. In 1988, Walia et al. [3] introduced the first nickel-titanium (NiTi) endodontic instruments, which revolutionized root canal preparation. This major impact relates to two properties inherent to NiTi shape memory and super elasticity - allied to high resistance to corrosion and biocompatibility [4]. The performance of NiTi alloy permitted the development of engine-driven rotary files operated in continuous rotation or reciprocating motion. Despite the advantages of NiTi rotary instruments, these files are still susceptible to fracture as a result of fatigue, torsional failure, or a combination of both $[5,6]$. In recent years, in an attempt to enhance the efficiency and safety of rotary files while minimizing the risk of fracture, manufacturers have invested in researching novel heat treatments to enhance the mechanical properties of NiTi instruments. M-Wire and, more recently, controlled memory
NiTi files were developed as a result of this initiative [7-9]. This study aimed to compare the flexibility, cyclic fatigue, and torsional resistance of three different NiTi alloys; Vortex M Wire (Dentsply Tulsa Dental, Tulsa, OK, USA), Vortex Blue (Dentsply Tulsa Dental, Tulsa, OK, USA) and Race (FKG Dentaire, La Chauxde-Fonds, Switzerland) rotary files, in order to verify whether different heat treatments resulted in mechanical benefits when used for preparation of curved root canals.

\section{Materials and Methods}

In this study, a total of 120 NiTi files were tested: 40 Profile Vortex Blue (Dentsply Tulsa Dental, Tulsa, OK, USA), made of controlled memory NiTi; 40 Profile Vortex (Dentsply Tulsa Dental, Tulsa, OK, USA), made of M-Wire; and 40 Race files (FKG Dentaire, La Chaux-de-Fonds, Switzerland), made of conventional NiTi alloy. Race files were established as the control group. All instruments tested had $25 \mathrm{~mm}$ length with $0.40 \mathrm{~mm}$ tip

*Corresponding Author:

Rodrigo Sanches Cunha DDS, MSc, PhD,

Department of Restorative Dentistry D227 A - 780 Bannatyne Avenue Winnipeg, MB R3E 0W2, Canada.

Tel: 1- 204-789-3284

E-mail: rodrigo.cunha@umanitoba.ca

Received: May 19, 2016

Accepted: June 6, 2016

Published: June 7, 2016

Citation: Lopes HP, Lopes WSP, Vieira VTL, Elias CN, Cunha RS (2016) Evaluation of the Flexibility, Cyclic Fatigue, and Torsional Resistance of Rotary Endodontic Files Made of Different Nickel-Titanium Alloys. Int J Dentistry Oral Sci. S8:001, 1-5. doi: http://dx.doi.org/10.19070/2377-8075-SI08001

Copyright: Cunha RS ${ }^{\circ}$ 2016. This is an open-access article distributed under the terms of the Creative Commons Attribution License, which permits unrestricted use, distribution and reproduction in any medium, provided the original author and source are credited. 
diameter and 0.04 taper. Ten specimens from each manufacturer were used in each test.

\section{Cantilever bending test}

The instruments' flexibility was analyzed by exposing the files to a cantilever bending resistance test using a universal testing machine (Emic, DL10000, Paraná - Brazil). Briefly, a $20 \mathrm{~N}$ load was applied by means of a stainless steel wire measuring $30 \mathrm{~cm}$ in length and $0.3 \mathrm{~mm}$ in diameter, with one end attached to the cross head and the other end fastened at $3 \mathrm{~mm}$ from the instrument tip (load application point). The tips of the instruments tested were subjected to a 45-degree displacement, within the elastic limit of the alloy. Testing was conducted at a speed of $15 \mathrm{~mm} / \mathrm{min}$.

\section{Rotating-bending test}

Instruments were subjected to static and dynamic tests, as described in a previous study [10].

Static test: Instruments were allowed to rotate clockwise in a simulated canal with fixed torque of $3 \mathrm{~N}$ and $300 \mathrm{rpm}$ speed, until occurrence of fracture. The time (in seconds) to fracture was multiplied by the number of rotations per second to determine the number of cycles to fracture (NCF).

Dynamic test: Instruments were subjected to the same protocol as in the static test, but the apparatus was set to move axially with an amplitude of $3 \mathrm{~mm}$ every 2 seconds.

In both tests, the moment of fracture was established visually and recorded by the same operator. NCF results were subjected to statistical analysis.

\section{Torsional resistance test}

Clockwise torsion without axial load was applied to the files using an apparatus attached to a universal testing machine (EMIC, DL 10000), as previously described [11]. The maximum rotation (degrees and turns) and maximum torque to fracture of each instrument were continuously monitored using a computer connected to the universal testing machine.

\section{Scanning Electron Microscopy (SEM) analysis}

SEM was used to determine the type of fracture and presence of plastic deformation in the helical shaft analyzed the fracture surface and the helical shaft of the fractured files.

\section{Statistical analysis}

Statistical analysis of the data was conducted by multiple comparisons testing using ANOVA and Student-Newman-Keuls test. The significance level was set to $5 \%(\mathrm{P}<0.05)$.

\section{Results}

\section{Flexibility (cantilever bending test)}

The mean and standard deviation for flexibility, measured by the load required to bend the files to 45 degrees, are shown in Table 1.
No significant difference was observed between Profile Vortex M Wire and Race $(\mathrm{P}>0.05)$. On the other hand, Profile Vortex Blue files were significantly more flexible than Profile Vortex M Wire and Race $(\mathrm{P}<0.05)$.

\section{Static rotating-bending test}

The mean and standard deviation for resistance to cyclic fatigue in the static rotating-bending test, defined by the NCF of the instruments tested, are also shown in Table 1. No statistically significant difference was found between Profile Vortex M-Wire and Race files $(\mathrm{P}>0.05)$. Nonetheless, Profile Vortex Blue were significantly more resistant in the static rotating-bending test than Race and Profile Vortex M-Wire files $(\mathrm{P}<0.05)$.

\section{Dynamic rotating-bending test}

The mean and standard deviation for resistance to cyclic fatigue in the dynamic rotating-bending test, measured by the NCF of the instruments tested, are presented in Table 1. Statistically significant difference was observed between all groups, in the following order: Profile Vortex Blue > Profile Vortex M-Wire > Race $(\mathrm{P}<0.05)$.

Comparison between the data obtained in the dynamic and static fatigue tests for instruments of the same brand showed that the dynamic testing model extended the NCF of all files $(\mathrm{P}<0.05)$.

\section{Torsional resistance test}

Table 1 shows the mean and standard deviation for the maximum rotation (degrees and turns) and the maximum torque to fracture the instruments in the torsional resistance test. Statistical analysis showed statistically significant difference between Profile Vortex $\mathrm{M}$ Wire files and the other instruments tested $(\mathrm{P}<0.05)$ in terms of the maximum rotation to fracture (degrees and turns). No significant difference was observed between Profile Vortex Blue and Race files $(\mathrm{P}>0.05)$. As for the maximum torque, statistical analysis revealed significant difference between the three groups, in the following order: Profile Vortex Blue $>$ Profile Vortex M Wire $>$ Race $(\mathrm{P}<0.05)$.

\section{SEM analysis}

After the rotating-bending tests, the fracture surfaces of all file presented features of ductile fracture (Figure 1). Evidence of ductile fracture was also observed on the fracture surface of instruments subjected to torsional resistance tests. All the instruments tested showed plastic deformation (helical distortion) (Figure 2).

\section{Discussion}

Use of NiTi alloy for production of endodontic files has brought great advancement to Endodontics, especially considering the mechanical challenges encountered during preparation of curved root canals $[12,13]$.

The instruments tested in the present study had similar design, length, taper, and diameter at $\mathrm{D}_{0}$, but were subjected to different heat treatments during the manufacturing process. This allowed 
Figure 1. Rotating - bending fracture. Ductile - type fracture surface: (A and B) ProFile Vortex Blue file; (C and D) ProFile Vortex file; (E and F) Race file (control group).
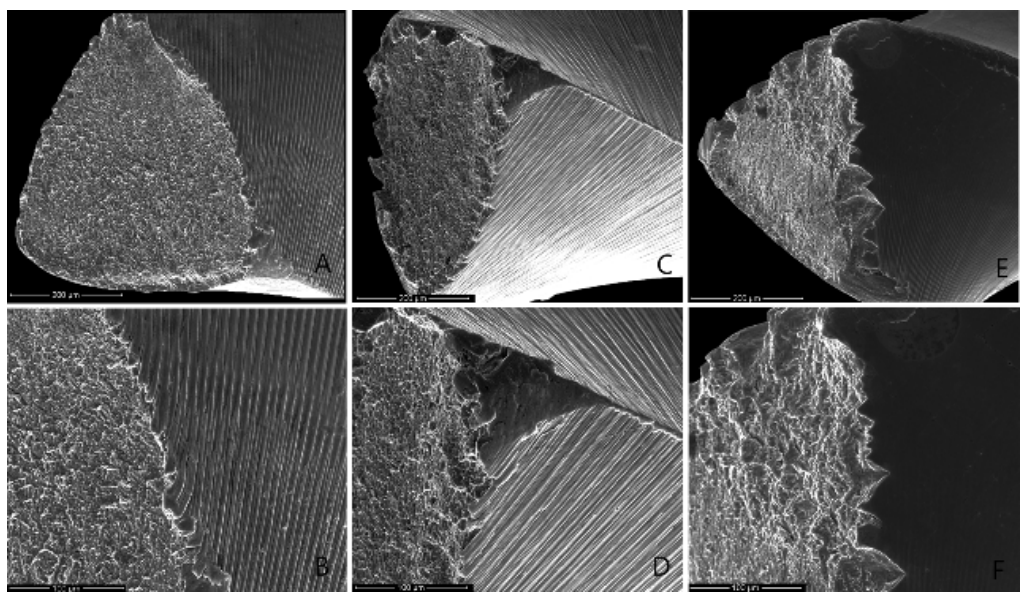

Figure 2. Torsional fracture. Ductile - type fracture surface showing plastic deformation on the helical shaft of the instruments: (A and B) Profile Vortex Blue file; (C and D) Profile Vortex file; (E and F) Race file (control group).
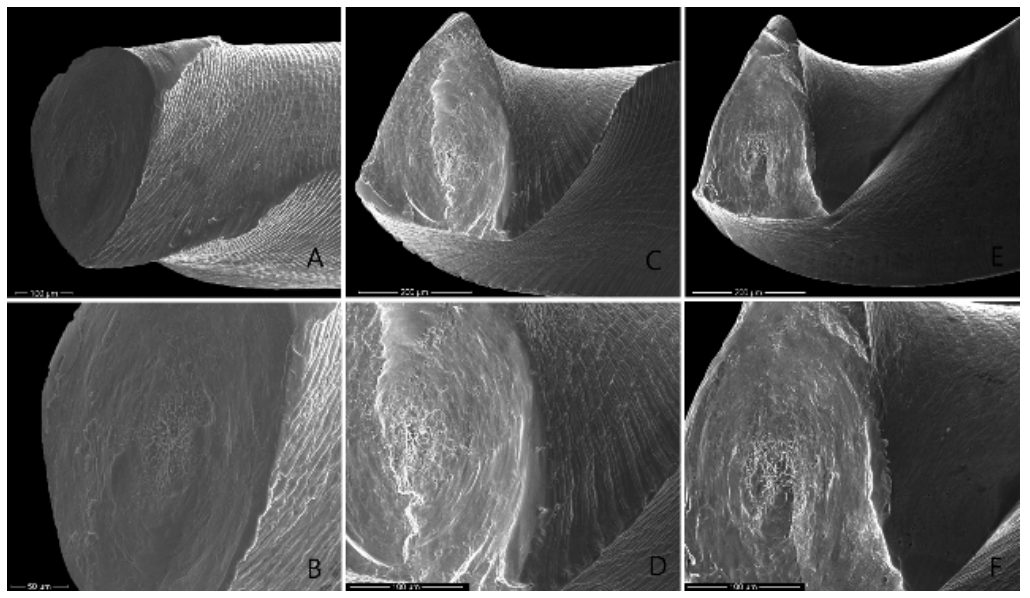

Table 1. Mean ( \pm standard deviation) results from the flexibility (cantilever bending), rotating-bending, and torsional resistance tests.

\begin{tabular}{|c|c|c|c|c|c|c|}
\hline \multirow{2}{*}{ Instruments } & \multirow{2}{*}{ Flexibility (g) } & \multicolumn{2}{|c|}{ Rotating-bending test (NCF) } & \multicolumn{2}{c|}{ Maximum rotation } & $\begin{array}{c}\text { Maximum } \\
\text { torque }(\mathrm{g} \cdot \mathrm{mm})\end{array}$ \\
\cline { 3 - 7 } & & Static model & Dynamic model & Degrees & Turns & \\
\hline Profile Vortex & $268.08(12.32)$ & $262.5(278.2)$ & $698.7(106.96)$ & $917.1(119.49)$ & $2.48(0.3)$ & $2139.69(145.68)$ \\
\hline $\begin{array}{c}\text { Profile Vortex } \\
\text { Blue }\end{array}$ & $231.89(17.14)$ & $866.5(166.87)$ & $1406.5(272.32)$ & $752.27(96.94)$ & $2.09(0.27)$ & $2732.03(425.32)$ \\
\hline Race & $275.22(5.91)$ & $270.6(40.01)$ & $414.4(36)$ & $735.08(90.04)$ & $2.04(0.25)$ & $1784.95(154.85)$ \\
\hline
\end{tabular}

for a realistic comparison of the influence of the type of NiTi alloy on the mechanical behavior of these files. The flexibility of an endodontic instrument is an important determinant of resistance to fatigue and torsion [6]. Moreover, use of flexible instruments lowers the risk of canal transportation, ledging, or perforations. During the rotating-bending tests, the instruments were allowed to rotate freely within the root canal without the interference of torsion, which could also have led to fracture $[5,10]$. This test generated repetitive cycles of traction and compression loads at the point of maximum flexure in the curved segment of the canal, until occurrence of fracture [14]. A relevant aspect to be considered in the present study is that the results from the static and dynamic tests were compared not only between the groups, but also within the groups of instruments. The number of cycles to fracture (NCF) was significantly greater in the dynamic model than in the static model, even between instruments of the same brand. This probably occurred because in the static test, compression and traction loads are concentrated in a single area of the instrument shaft. Contrastingly, in the dynamic model, these compression and traction loads are distributed throughout a greater area along the instrument shaft. Consequently, in the dynamic model, crack propagation is delayed and the instrument's resistance to cyclic fatigue is increased [10, 15]. Still, comparison between the controlled memory, M-Wire, and conventional NiTi files showed that the NCF of Profile Vortex Blue was significantly higher than that of Profile Vortex M-Wire and Race 
(conventional NiTi), both in the static model and the dynamic model. Conversely, when the NCF of Profile Vortex M-Wire files was compared with the NCF of Race files in the static model, their values did not differ significantly, while in the dynamic model Profile Vortex M-Wire files had significantly higher NCF values than Race. The most likely explanation for this difference in mechanical behavior may be attributed to the different heat treatments of M-Wire, controlled memory, and conventional NiTi alloys during the manufacturing process [16-22].

The heat treatment by which controlled memory NiTi is produced is a relatively new field in Endodontics research and the manufacturers have made limited information on this process available. Studies by Thompson 2000 [4], Kuhn et al. 2001 [20], Johnson et al. 2008 [21], and Gutmann \& Gao 2012 [6] agree with the notion that the type of heat treatment dispensed to the alloy, in conjunction with instrument configuration, influence the mechanical properties of the material by significantly affecting the flexibility of the resulting instrument. Lopes et al. 2013 [22] compared the mechanical behavior of endodontic files made of conventional NiTi, M-Wire, and R-phase NiTi. The authors concluded that Profile Vortex M-Wire files did not perform better in terms of flexibility and fatigue, probably due to differences in instrument design and size among the instruments tested in their study. Shen et al. 2012 [23] and Shen et al. 2013 [24] reported that controlled memory files are more flexible and resistant to fatigue; these authors believe that this behavior is related to the heat treatment of the alloy. In our study, Profile Vortex Blue showed greater fatigue resistance and flexibility in comparison with Profile Vortex M Wire and Race files (conventional NiTi control group). The mechanical behavior of Profile Vortex Blue is likely to have delayed crack propagation along the instrument shaft. These results are in agreement with some previous studies [23-25].

Regarding the torsional resistance test, the two parameters evaluated are related to the maximum rotation (degrees and number of turns). According to some authors, the most important determinant of torsional fracture is the maximum torsional angle until fracture, rather than the maximum torque $[11,26]$. During clinical use, the maximum torsional angle may serve as a safety factor by allowing the operator to visually detect plastic deformation of the rotary file upon its removal from the canal (thus preventing re-insertion). In other words, instruments with great maximum torsional angle values are capable of withstanding great elastic and plastic deformation until failure. In order to improve the safety of engine-driven rotary files, manufacturers adopt torque values below the maximum torque that could lead the instrument to torsional failure.

With reference to the maximum torque results in the present study, Profile Vortex Blue had significantly greater torque values than those of Profile Vortex M-Wire, which in turn were significantly greater than those of Race files. These results corroborate those from Peters et al. 2012 [26], who reported that controlled memory NiTi instruments have great torsional resistance. On the other hand, the maximum torsional angle values showed no significant difference between Profile Vortex Blue and Race files. Nevertheless, Profile Vortex M-Wire files were capable of withstanding greater torsional angles than the controlled memory and conventional NiTi files. This discrepancy of results has been previously reported in the literature $[9,19,22,25,26]$.
Another important consideration concerning the mechanical behavior and clinical performance of endodontic instruments relates to apical widening the choice of size 40 files with 0.04 taper in the present study was based on previous works suggesting that the final apical diameter should range from 0.35 to $0.60 \mathrm{~mm}$ $[27,28]$. Therefore, development of instruments with greater diameter and taper while maintaining the flexibility, torsional resistance, and fatigue resistance has been a constant pursuit for the manufacturers, who aim to develop instruments that can be safely used in the preparation of curved canals.

SEM analysis showed that the fracture surfaces of all files presented features of ductile fracture, regardless of the type of alloy and of the test (torsion or rotating-bending resistance). The helical shafts of all the instruments subjected to the torsional resistance assay suffered plastic deformation [29].

Based on these results, our conclusion is that Profile Vortex Blue files have greater flexibility, resistance to fatigue, and torsional resistance when compared to Profile Vortex M-Wire and conventional NiTi Race files. This study suggests that controlled memory NiTi may represent advancement for preparation of severely curved root canals.

\section{References}

[1]. Schilder H (1974) Cleaning and shaping the root canal. Dent Clin North Am 18(2): 269-296.

[2]. Schäfer E, Schlingemann R (2003) Efficiency of rotary nickel-titanium K3 instruments compared with stainless steel hand K-FlexoFile. Part 2. Cleaning effectiveness and shaping ability in severely curved root canals of extracted teeth. Int Endod J 36(3): 208-217.

[3]. Walia H, Brantley WA, Gerstein H (1988) An initial investigation of the bending and torsional properties of Nitinol root canal files. J Endod 14(7): 346-351.

[4]. Thompson SA (2000) An overview of nickel-titanium alloy used in dentistry. Int Endod J 33(4): 297-310.

[5]. Lopes HP, Vieira, Márcia VB, Elias, Carlos N, Siqueira Jr, José F,Mangelli, Marcelo, et al. (2013) Fatigue life of WaveOne and ProTaper instruments operated in reciprocating or continuous rotation movements and subjected to dynamic and static tests. Endo 7(3): 217-222.

[6]. Gutmann JL, Gao Y (2012) Alteration in the inherent metallic and surface properties of nickel-titanium root canal instruments to enhance performance, durability and safety: a focused review. Int Endod J 45(2): 113-128.

[7]. Gao Y, Shotton V, Wilkinson K, Phillips G, Ben Johnson W (2010) Effects of raw material and rotational speed on the cyclic fatigue of Profile Vortex file rotary instruments. J Endod 36(7): 1205-1209.

[8]. Oh SR, Chang SW, Lee Y, Gu Y, Son WJ, Lee W, et al., (2010) A comparison of nickel-titanium rotary instruments manufactured using different methods and cross sectional areas: ability to resist cyclic fatigue. Oral Surg Oral Med Oral Pathol Oral Radiol Endod 109(4): 622-628.

[9]. Shen Y, Qian W, Abtin H, Gao Y, Haapasalo M (2011) Fatigue testing of controlled memory wire nickel-titanium rotary instruments. J Endod 37(7): 997-1001.

[10]. Rodrigues RCV, Lopes HP, Elias CN, et al. (2011) Influence of different manufacturing methods on the fatigue of rotary nickel-titanium endodontic instruments. J Endod 37(11): 1553-1556.

[11]. Lopes HP, Elias CN, Vedovello GAF, Bueno CES, Mangelli M, Siqueira JF $\mathrm{Jr}$ (2011) Torsional resistance of retreatment instruments. J Endod 37(10): $1442-1445$.

[12]. Shäfer E, Dammaschke T (2006) Development and sequelae of canal transportation. Endod Topics 15(1): 75-90.

[13]. González Sánchez JA, Duran-Sindreu F, de Noé S, Mercadé M, Roig M (2012) Centering ability and apical transportation after overinstrumentation with ProTaper Universal and ProFile Vortex instruments. Int Endod J 45(6): 542-551.

[14]. Lopes PH, Moreira LJE, Elias NC, Almeida AR, Neves SM (2007) Cyclic fatigue of ProTaper instruments. J Endod 33(1): 55-57.

[15]. Yao JH, Schwartz SA, Beeson TJ (2006) Cyclic fatigue of three types of ro- 
tary nickel-titanium files in a dynamic model. J Endod 32(1): 55-57.

[16]. Kim HC, Yum J, Hur B, Cheung GS (2010) Cyclic fatigue and fracture characteristics of ground and twisted nickel-titanium rotary files. J Endod 36(1): 147-152.

[17]. Shen Y, Qian W, Abtin H, Gao Y, Haapasalo M (2011) Fatigue testing of controlled memory wire nickel-titanium rotary instruments. J Endod 37(7): 997-1001.

[18]. Shen Y, Zhou HM, Campbell L, et al. (2011) Metallurgical characterization of controlled memory wire nickel-titanium rotary instruments. J Endod 37(11): 1566-1571.

[19]. Santos LA, Bahia MGA, Las Casas EB, Buono VTL (2013) Comparison of the mechanical behavior between controlled memory and superelastic nickel-titanium files via finite element analysis. J Endod 39(11): 1444-1447.

[20]. Kuhn G,Tavernier B, Jordan L (2001) Influence of Structure on NickelTitanium Endodontic Instruments Failure. J Endod 27(8): 516-520.

[21]. Johnson E, Lloyd Adam, Kutller S, Namerow K (2008) Comparison between a novel nickel-titanium alloy and 508 nitinol on the cyclic fatigue life of Profile 25/.04 rotary instruments. J Endod 34(11): 1406-1409.

[22]. Lopes HP, Gambarra- Soares T, Elias CN, et al. (2013) Comparison of the mechanical properties of Rotary instruments made of conventional nickeltitanium wire, M- Wire, or nickel-titanium alloy in R-phase. J Endod 39(4): 516-520. http://www.ncbi.nlm.nih.gov/pubmed/23522548

[23]. Shen Y, Qian W Abtin, Gao Y, Haapasalo M (2012) Effect of environment on fatigue failure of controlled memory wire nickel-titanium rotary instruments. J Endod 38(3): 376-380.

[24]. Shen Y, Coil JM, Zheng Y, Haapasalo M (2013) HyFlex nickel-titanium rotary instruments after clinical use: metallurgical properties. Int Endod J 46(8): 720-729.
[25]. Gao Y, Gutmann JL, Wilkinson K, et al. (2012) Evaluation of the impact of raw materials om the fatigue and mechanical properties of Profile Vortex rotary instruments. J Endod 38(3): 398-401.

[26]. Peters OA, Gluskin AK, Weiss RA, Han JT (2012) An in vitro assessment of the physical properties of novel Hyflex nickel-titanium rotary instruments. Int Endod J 45(11): 1027-1034.

[27]. Kerekes K, Tronstad L (1977) Morphometric observations on root canals of the human molars. J Endod 3(3): 114-118.

[28]. Wu MK, Wesselink PR, Walton RE (2000) Apical terminus location of root canal treatment procedures. Oral Surg Oral Med Oral Pathol Oral Radiol En$\operatorname{dod} 89$ (1): 99-103.

[29]. Yum J, Cheung GSP, Park JK, Hur B, Kim HC (2011) Torsional strength and toughness of nickel-titanium rotary files. J Endod 37(3): 382-386.

Special Issue on
"Endodontics: Treatment \& Technology"
Theme Edited by:
Roberta Pileggi, Associate Dean \& Director, University of
Florida, USA. E-Mail: RPILEGGI@ dental.ufledu
Ahmad A Madarati, Assistant Professor, Taibah University,
Saudi Arabia. E-Mail: amadarati@taibahu.edu.sa

